\title{
The Creative Other: marginalization of and from the creative industries
}

\section{Introduction}

The paper attempts to apply the concept of Other to the relationship between the creative industries and its 'non-creative' counterparts; as well as to challenge the constituency of the creative industries themselves.

The lens of Other offers a theoretical understanding of the marginalisation of and within the creative industries. Drawn from Edward Said's notion of the Oriential Other and deployed in studies of gender, ethnic, class and sexual minorities; the practice of 'othering' has been shown to be widespread and to cut across communities, sectors and disciplines. In this paper, it is argued that 'othering' occurs between creative workers as can be seen by the labour force profiles of creative industries, and also at an industrial level in terms of the usefulness and value of the creative sectors to non-creative industries.

2015 saw the closure of Australia's first Creative Industries Innovation Centre after a six-year tenure. Launched in 2009 by the Australian Government's Department of Industry, its explicit mission was to support creative enterprises with business evaluations and expert advice (Andersen, Ashton and Colley 2015). However, after 2015, the department refocused its efforts on five key growth sectors, and the creative industries was subsumed under 'enabling technology and service providers'. In effect, this saw the creative industries sidelined and subsumed into a category of 'enabling' sectors, whose value was determined by their usefulness to the other four areas of growth, namely advanced manufacturing; food and agribusiness; medical technologies and pharmaceuticals; and oil, gas and energy resources.

This macro-level erasure of the creative industries represents a kind of 'othering', and is reflected within and across creative sectors at a more human level. This paper seeks to look at the patterns of 'othering' that occur when traversing the creative industries, and thus draws on literature that spans these disciplines to explore the intersections and divergences.

Deploying the notion of Other to the creative industries allows us to consider the structural relations with 'non-creative' industries, and to acknowledge processes of 'othering' that exclude in ways that are typical of other sectors. While creativity and creatives are often celebrated for their difference or Otherness, this paper seeks to contribute a more sobering representation of how 'othering' operates in the creative industries and how those who have been subject to it speak to this marginalisation.

\section{The Creative Other: a life in service}

There has been an interesting alignment between academic literature and government policy regarding creative industries, with the former arguably 
influencing the latter in the Australian context. There is a general consensus that the creative industries include music and the performing arts, architecture, design and the visual arts, print and broadcast media, digital and interactive media, advertising and marketing. There is also agreement that the creative capital generated by such industries is crucial to economic growth. This was acknowledged as early as 1994 in Australia's first cultural policy, Creative Nation:

'Culture creates wealth. Culture employs. Culture adds value, it makes an essential contribution to innovation, marketing and design. It is a badge of our industry. The level of our creativity substantially determines our ability to adapt to new economic imperatives. It is essential to our economic success.' (Australian Government 1994)

This policy recognised the economic value of culture and creativity. This understanding of creative industries as 'a significant stakeholder in the broader economy' was not only echoed in subsequent government reports (Cultural Ministers Council 2008), but also saw it move beyond the government's arts and cultural ministries into the portfolios of the Department of Broadband, Communications and the Digital Economy and Department of Industry, Innovation, Science and Research (DIISR):

'Creativity is the key to innovation, and innovation drives growth, sustainability and prosperity... Creative industries are part of the emerging services economy in Australia, contributing more to the economy both in terms of output and employment than is commonly known.' (Australian Government 2011)

The academic investigations of the Queensland University of Technology's (QUT) Australian Research Council (ARC) Centre of Excellence for Creative Industries and Innovation has helped to frame the work of the creative industries in relation to 'non-creative' industries. That is, it is the work of people who are located in these creative sectors, the human activities related with the production, distribution, exchange and consumption of creative goods and services (Higgs et al 2008), when applied to the non-cultural or non-creative industries, that together constitute the creative economy. The emphasis has been less on the creative industries themselves and the work that takes place within them; rather, there has been more focus on the work of 'embedded creatives', those in creative occupations but employed outside of creative industries (Creative Industries Innovation Centre 2013) as these make up the majority of the creative workforce. Part of the process of assessing the creativity of occupations involves their contribution to the value chain (Bakhshi et al 2013), or how they add value to other sectors, and specifically in terms of dollars and GDP (Flew 2014).

Hearn et al (2014) define the work of embedded creatives as service occupations as they are 'providers of creative services'. That they are 'in service' to - or even servants of - other sectors of the economy means that they have been subsumed by other industries and made invisible. Despite that embedded creatives are over-represented in the creative workforce, what is implied here is that the work 
of embedded creatives is less attractive and celebrated than the work of specialist creatives and cultural producers such as filmmakers, musicians and performers.

Thus, there are different dynamics of marginalisation taking place: of the creative industries themselves as well as within them. At one level, there is a hierarchy within the creative industries whereby those engaged in cultural production receive more prominence and attention on their own terms and in academic studies (ibid), but constitute a minority. Therefore, it is the majority of workers within the creative industries, those engaged in the provision of creative services to other industries, who are marginalised by their invisibility. At another level, the legitimacy of the creative industries is only recognised through its service and relationship to others.

The characteristics of such marginalisation - invisibility, lack of recognition, low status identity that only has value in its connection to something of higher status - are more commonly seen in minorities who are pegged as Other. Groups and communities that have been identified as Other include:

- women, whose value has been regarded as less than men across issues ranging from wage inequality to the Oedipex complex in Freudian psychoanalysis, to representation in film where female characters function as objects of the 'male gaze' (Mulvey 2015);

- the working class, whose labour generates wealth for another class, the 'bourgeoisie' or owners of means of production (Marx 1974);

- ethnic minorities, whose ethnicities are fetishized for the purposes of maintaining a dominant White Anglo-Celtic national identity (Hage 2002; Ang 2003);

- sexual minorities, those who occupy queer positions outside of heteronormative expectations (Baker 2011, Harris 2013).

In a similar sense, the creative industries can also be classified as Other in that they do not occupy a position of dominance. It is non-creative industries such as manufacturing, wholesale trade and public administration that benefit most from exploiting creative labour (Creative Industries Innovation Centre 2013). This relationship between the creative and non-creative industries can be likened to Said's (1995) notion of Orientalism. The concept of the Orient was invented by Europe as a way of forging an identity for the West, while simultaneously co-opting the Orient for its economic growth through trade and cheap labour. Despite the East being constructed as an alien entity and everything that Europe was not, it was still subsumed by a Western identity that claimed to represent and speak for it. This parallels the dichotomy between creative and non-creative industries, and the subordination of embedded creativity within the latter. Embedded creatives do not have their own platform for representation, so are 'spoken for' by the non-creative industry of which they are part.

One of the critical features of having an Other identity is being denied selfrepresentation. The result of this, in Orientalist terms, is having an identity constructed on your behalf. The East/West dichotomy gave rise to the 'native 
expert' and 'ignorant tourist' (ibid). The Eastern Orient was portrayed by Europe as exotic, mysterious, dangerous and superstitious (Phillips 2014), with ethnic stereotypes such as the humorous Chinese servant and the passive Filipino houseboy (Berelson and Salter 1973). Likewise, it could be argued that there are equivalent cariacatures of the Creative Other that emerge from non-creative industries and managers.

\section{An Other Disposition}

Indeed, the skillsets of creatives have been described by what they are not. They are differentiated from 'number-crunching' and cost management, which are considered in diametric opposition to being intuitive, subjective and experimental (Sorrell 2015). Townley et al's (2009) representation of creative workers as a 'motley crew' suggests skills that are difficult to classify or manage within traditional organisational structures. Creatives are characterised as misfits, rule-breakers, as marginal:

'They are at the intersection between social groups, able to pick up, transfer and adapt ideas and practices, thereby creating new ways of understanding...they are transgressive; their actions not bounded by the performance rules of the community.' (ibid)

Embedded creatives, in particular, work at the intersection of different disciplines, and so are involved a constant process of boundary-crossing (Hearn et al 2013), but at the peripheries of those disciplines where they often go unrecognised. Therefore, it is unsurprising that Thomson et al (2009) identify creatives as experiencing higher levels of dissociation or marginalisation than non-creative people, often as a result of trauma.

Creativity becomes intertwined with identity, subjectivity and eccentricity (Caves 2000) but also an entrepreneurial mindset (Gill and Pratt 2008) as they realise they must compete in an overcrowded creative labour market. They are more likely to be overeducated and overqualified in order to combat the likelihood of underemployment as a creative worker (Menger 2006).

All the abovementioned qualities that characterise the Creative Other can also be found in minority groups and communities that identify as Other. Their minority status - a product of particular intersections of class, gender and ethnicity results in 'different ways of knowing' (Luttrell 1988; Haraway 1988), subjectivities that emerge from outside of a dominant group or culture. This 'intersectionality' refers to the interaction between categories of difference. Originating from feminist theory, it proposed that with each category of Otherness comes further marginalisation (Davis 2010).

'Interest in intersectionality arose out of a critique of gender-based and racebased research for failing to account for lived experience at neglected points of intersection - ones that tended to reflect multiple subordinate locations as opposed to dominant or mixed locations.' (McCall 2005) 
Being Other is about being subordinated or located in an inferior position in a relationship of power (Schippers 2007). We see this in de Beauvoir's (1993) argument that women are the 'second sex', whereby female identity is constructed in opposition to and by a normative male identity. Like the duality of creative and non-creative industries, feminine qualities are associated with intuition and nurturing, while masculinity implies rationality and logic (Soskice 1994).

Similarly, ethnic minorities (both immigrant and indigenous) find themselves defined relative to their non-whiteness (Solomos and Back 1996) within host societies where whiteness is assumed to be the norm. Although there is huge diversity across ethnicities, the claiming of a collective identity - such as 'black' is a symbolic expression of Otherness, of solidarity in their experience racism, of oppression as well as resistance (Ross 1996):

'What these communities have in common, which they represent through taking on the "black" identity, is not that they are culturally, ethnically, linguistically or even physically the same, but that they are seen and treated as "the same" (ie non-white, "other") by the dominant culture' (Hall 1992).

This has parallels with the Creative Other: the adoption of the title of 'creative' is not about fitting a particular profile, but rather a declaration of a unique oppositional, misfit identity.

The ethnic Other, like the embedded creative, is also transgressive in that they report being 'between two worlds' (Leung 2005; Wakil et al 1981):

'... "other" people are left with two options: either enter the game or be excluded...either integrate/assimilate or remain an outsider... This ensures that the position of the non-white in a white-dominated world...is always necessarily and inescapably an "impure" position, always dependent on and defined in relation to the white/Western dominant.' (Ang 2003)

The identities that are produced through traversing of cultures or worlds have also been called 'in-between', hybrid and multidimensional (Bhabha 1994; Bigelow 2011). The price of occupying this 'third space' is having the necessary skillsets to navigate and operate effectively across different languages, cultures and worlds.

Despite having these additional capabilities, the ethnic Other finds themselves more likely to be unemployed than their white/Western counterparts (Fibbi et al 2006; Silberman et al 2007; Soysal 2001). Similarly, Richards (2016) contends that queer creative practice is inherently innovative because it involves a constant process of deconstructing and reconstituting intertwined subjectivities, yet Gay and Lesbian publishing has experienced a severe demise.

There are commonalities here with the Creative Other who is also prone to higher levels of unemployment (but due to labour oversupply rather than discrimination), but remedy this by working outside of the creative industries in 
non-creative sectors.

\section{Diversity as inherent to creativity: how creative can the creative industries be?}

'There is an overall recognition within the creative industries that cultural diversity encourages creativity and innovation...' (Smallbone et al 2005)

Given the parallels between the Creative Other and various Other identities, one would expect to see a good representation of the latter in the creative industries. The role of the creative industries as service providers to 'major player' noncreative industries, should speak to those who see themselves as part of marginalized minorities who have to move between mainstream worlds and their niche cultures. The situated knowledges and identities of creatives also reflect the 'motley' subjectivities of those outside of dominant gender, class, ethnic and sexual categories, and so, the creative industries ought to appeal and be disposed to Others.

Although working in the creative industries may be alluring because it is perceived as diverse and egalitarian (Gill 2002), it has been widely acknowledged in industry reports and media that the Other is underrepresented in the creative industries. Women are in the minority the digital sector, comprising only $25 \%$ of ICT workers and earning $20 \%$ less than men (Deloitte Access Economics 2015: 11). In Australia, only 23.3\% of architects are women (Roan and Stead 2013), while in the UK, this has not risen above $20 \%$ since the mid-2000s (Sang et al 2007). In the Australian film industry in 2015, only $16 \%$ of feature films were directed by women, $20 \%$ written by women and $29 \%$ produced by women. In the UK, only $14 \%$ of feature films had female directors in the period 2009 to 2013; while in the US it was only 6\% (Davidson 2015). There has been an increase of 1\% from 1998 to 2012 of women working on the top 250 grossing films in Hollywood (Lauzen 2012).

'It is pretty plain across the sector that women cluster on the production side, as producers, line producers, production managers and post production supervisors. They are asked to be the handmaidens, the patient supporters exercising all those communal traits. This vision is also a ludicrous cliché, but it reflects the way women flow around the centres of power, towards the opportunities they are offered.' (Screenhub 2015)

It is notable that the role of women in supporting positions mirrors the way the creative industries are portrayed as 'handmaidens' to other industries. This is also borne out in the academic literature, which has found that in the film and television industries, women are over-represented in 'backstage' areas such as hair, makeup and wardrobe, while under-represented in key creative roles such as writing, directing and cinematography (Conor et al 2015). Relative to men, women in the creative industries fare worse in terms of pay, employment numbers, contractual status and seniority (Dodd 2012).

Even more under-represented than women are ethnic minorities, who constitute 
a smaller proportion of the creative industries than other non-creative industries (Thanki and Jeffries 2007; Oakley 2013). This is despite concerted efforts to encourage wider participation by 'non-traditional' (hence Othered) students in the creative disciplines within higher education. Furthermore, 'non-traditional' graduates earn less and take more time to find permanent employment (Allen et al 2013). Indeed, Allen et al (ibid) argue that student work placements in the creative industries privilege ways of being that are particularly 'masculinised' and middle-class.

'Women, ethnic minorities and the working class are failing to gain parity of entry to and outcomes within the creative industries, with white middle class males faring much better.' (Eikhof and Warhurst 2013)

Florida (2002) agrees that there are 'gaping holes' in creative economies where ethnic minorities are excluded. The US technology sector scores low on his diversity index because of the notable absence of African-American and nonwhite Others. In London's creative industries, Asians are under-represented overall but are highly concentrated and over-represented in the music, fashion and digital sectors (Smallbone et al 2005).

Although black culture influences the outputs of the creative industries, especially fashion and music, black people constitute smaller minorities in those sectors than in the community (Oakley 2006). Even in the music industry, music which is deemed 'underground' (and therefore Other as it is not mainstream) is often associated with 'black music' genres such as hip-hop, $r$ ' $n$ ' $b$, jungle and garage. This is indicative of the marginalisation of black artists and their creative output (Bose 2005).

Another term that is linked with being 'underground' (and thus an ethnic and creative Other) is 'underclass' (the socio-economic Other). Unlike black culture which has impacted creative industries while black creators are largely excluded from participating, the working class have actually, at times, dominated in certain sectors. Maconie (2015) asserts that the working class constitution of British popular music - which saw the advent of bands such as the Beatles, Manic Street Preachers, Pulp, Morrissey, Kaiser Chiefs and Arctic Monkeys - is now over:

'In the arts generally - music, theatre, literature for sure - it is clear that cuts to benefits, the disappearance of the art school... and the harsh cost of further and higher education are pricing the working class out of careers in the arts... What is unarguable is that a curious gentrification of pop culture is ongoing...'

In the media industries in the 1980s, more than half of leading journalists had had attended a state school. In 2006, this had dropped to only 14\% (Sutton Trust 2006). In 'new media' industries, Gill (2002) found that most workers were not earning enough from this kind of work alone, and needed to supplement their income with other types of work. This type of occupational profile aligns with low-income jobs that are typically done by women, ethnic minorities and the working class where more than one job is required to earn a living wage. 
While the findings clearly indicate a lack of ethnic and gender diversity in the creative industries (Creative and Cultural Skills 2008), the academic literature on exclusion within the creative industries seems to be focused on gender in/equality, and this is perhaps a reflection of hierarchies of Othering as it is to do with the availability of data about the ethnic and class backgrounds of the creative workforce. Nevertheless, more work in this area is needed, particularly that which gives voice to Others, not only to speak to their exclusion from the creative industries, but to the co-creation of strategies for ameliorating it. In particular, there has been little attention given to how sexual minorities participate and are represented in the creative industries. While Harris' (2012) study shows that there is still discomfort with sexual diversity in creative arts education, Richards (2016) posits that queer culture has been successfully mainstreamed in cinema through political support and the commercial success of events such as the Melbourne Queer Film Festival and Sydney Mardi Gras Festival.

\section{An Other perspective and creative intervention}

An example of an Other response to marginalization from the creative industries by those working within them can be seen in the series of infographics produced by Lee and Low Books, a publishing company committed to representing diversity in children's books. As a creative organization, it recognizes the lack of representation of Other identities in print media through its mission statement: 'about everyone, for everyone'.

The infographics are the output resulting from studies of diversity conducted by the company across a range of creative industries in the United States, including the technology sector, the film and television industry, publishing and theatre. They demonstrate an alternative way of disseminating knowledge that does not follow the conventions of industry reports or academic research, and in doing so, articulate the process of the Creative Other. They also speak from a position of Otherness as a creative industries company constituted mostly by people of Other identities. In addition, they speak directly to those creative industries in which marginalization of Others is so insistent, and present calls to action. Furthermore, they combine their voice with Others in the respective creative industry who are making interventions to address problems of representation.

The infographic concerning Silicon Valley (Lee and Low Books 2015) shows that among 183 board members from twenty major technology companies, only three members are black and one Hispanic. Examining ethnic diversity across companies such as Google, Facebook, Pandora, LinkedIn, Pinterest, eBay and Yahoo, it was found that 50\% of employees were white, 41\% Asian, 3\% Hispanic, $2 \%$ black and $4 \%$ other. This concurs with Florida's (2002) observation that the presence of a technology sector equates to an absence of people who identify as African American. The finding that, across 200 large, medium and small enterprises in Silicon Valley, only $18 \%$ of its labour force were women shows that gender inequality is even more concentrated than previously thought. The 
publication of the infographic on the blog of Lee and Low Books is combined with comment from ethnic minority women leaders from organisations such as Black Girls CODE, Intel Corporation, The Society for Diversity and Pinterest:

'Diversity discussions must be led by all people and they can't exclude divergent thoughts or beliefs'

'There is a need for some serious analysis and transformation of corporate culture to create more nurturing environments for women and people of color if we truly want to see the diversity numbers improve.'

Ethnic minority creative practitioners from the film, television and theatre industries were invited to respond to the infographics on the Academy Awards, Emmy Awards and Tony Awards. The research found that over its entire 87-year history up to 2015, 99\% of Best Actress Academy Award winners have been white, as have been Best Director winners, and 92\% of Best Actor winners. Of those who are eligible to vote in the Academy Awards, only $7 \%$ are people of color while $24 \%$ are female (Lee and Low Books 2014). In the 21 years of the Emmy Awards up to 2012, not one ethnic minority female has won Best Lead Actress in a Drama Series nor has a person of color ever won Best Director of a Comedy Series; and Best Director winners have been 95\% male (Lee and Low Books 2013). Similarly, over 31 years up to 2012, Tony Awards winners have been overwhelming white for Best Actress in a Play (90\%), Best Actor in a Play (94\%) and Best Director of a Musical (97\%); but there has been a higher proportion of people of colour winning Best Actress in a Musical (27\%), Best Actor in a Musical (13\%) and Best Director of a Play (12\%) (Lee and Low Books 2013a).

'So the issue is, how do we get more eclectic people into the room? How does the face of TV writing start to look more like the face of America?'

'No Asian American female playwright has ever been produced on Broadway. Ever.'

'On New York City stages during the 2011-2012 season...Caucasian actors filled $77 \%$ of all roles. Caucasians continue to be the only ethnicity to over-represent compared to their respective population size in New York City of the Tri-State area.'

Although the studies are US-based and not industry-wide surveys, they are incisive highlights of aspects of specific creative industries that have had minimal research attention both sectorally and academically. Perhaps more importantly, the film, television and theatre studies shift the focus away from workforce diversity profiles to examine what and who is publicly celebrated within those industries in their awards ceremonies. Another infographic specifically explores film content, the top 100 grossing sci-fi and fantasy movies in 2014. The research discovered that only eight of the movies had an ethnic minority protagonist, of which one was an animated character (Aladdin) and six were Will Smith. There were no key characters who were LGBTQ, and only 2\% 
with a disability (2014a). Representatives of equality advocacy groups Racebending.com and the Representation Project, were interviewed about the research:

'When you're talking about representation this low, it's hard to go anywhere but up.'

In investigating their own creative industry - publishing - the organization has not only sought input from writers, librarians and editors, but also scholars. Despite minorities constituting $37 \%$ of the US population and projected to increase to $57 \%$ by 2060 , only $10 \%$ of children's books contain multicultural content and this is remained consistent from 1994 to 2014 (Lee and Low Books 2013b). Looking at the New York Times Top 10 Bestsellers of adult fiction in 2012 , only 3 of the 124 authors were identified as ethnic minorities, with none being African American (Lee and Low Books 2013c).

The blog format through which the research is presented enables direct links to other non-academic studies, such as a librarian blogger's analysis of gender disparity in the New York Times Young Adult Bestseller list, or data collected by the Asian American Performers Action Coalition.

\section{Conclusions}

The research undertaken by Lee and Low Books articulate the different ways of thinking as represented by the Creative Other, but also alternative ways of being inherent in being of an Other identity. As part of the creative industries, the publishing company has applied their creative practice to the process of doing and disseminating research, such that it does not conform to conventional industrial and academic research outputs. Moreover, it has published the research to draw attention to their own marginalized position within the publishing industry, and to the Othering which occurs in the wider creative industries. In doing so, it dispels any illusions about diversity being intrinsic to those industries.

Across the research conducted by Others from within (such as Lee and Low Books) as well as the industry and academic literature, it is clear that the creative industries are no more diverse than other industries in terms of their gender, class and ethnic profile. The creative industries are constituted by diverse sectors but there is an alarming consistency in the ways that women, ethnic minorities and the working class have been excluded from participating in them. It is a narrative that is historically familiar in other industries.

However, given the prevailing and persistent assumptions that the creative industries are diverse and egalitarian, and that diversity is an absolutely necessary ingredient for creativity and innovation; it is unexpected of the creative industries. As such, it demonstrates that there are various contradictory axes of marginalization and exclusion at play. The promise and allure of the creative industries is strong, generating competition that favours those who are advantaged by mainstream, dominant class, gender, ethnicity and sexuality; yet creative practices and processes are explicitly niche, eccentric and independent. 
Also, the 'service' relationship and subordinate positioning of the creative industries to its non-creative counterparts resonates with the roles that women, ethnic minorities and the working classes have historically occupied as a result of their experience of discrimination. Paradoxically, this service role of the creative industries is now dominated by white, male, middle class privilege. Returning to the proposition that diversity is the mother of all creativity, it begs the question: how much more innovative could the creative industries potentially be with greater diversity?

\section{References}

Allen, Kim, Jocey Quinn, Sumi Hollingworth and Anthea Rose. 2013. "Becoming employable students and 'ideal' creative workers: exclusion and inequality in higher education work placements." British Journal of Sociology of Education 34 (3): 431-452.

Andersen, Lisa, Paul Ashton and Lisa Colley. 2015. Creative Business in Australia: Learnings from the Creative Industries Innovation Centre. Sydney: UTS ePress.

Ang, Ien. 2003. "I'm a Feminist, but... 'Other' women and postnational feminism." In Feminist Postcolonial Theory: A Reader, edited by Reina Lewis and Sara Mills, 190-206. London: Routledge.

Australian Government. October 1994. Creative nation: Commonwealth cultural policy. Office for the Arts. Accessed July 6, 2015. http://apo.org.au/node/29704

Australian Government. 2011. Creative Industries, a strategy for 21st century Australia. Department of Industry, Innovation, Science, Research and Tertiary Education (DIISR). Accessed July 6, 2015.

http://arts.gov.au/sites/default/files/creative-industries/sdip/strategic-digitalindustry-plan.pdf

Baker, Dallas. 2011. "Queering practice-led research: subjectivity, performative research and the creative arts." Creative Industries Journal 4(1): 33-51.

Bakhshi, Hasan, Alan Freeman and Peter Higgs. 2013. A dynamic mapping of the UK's creative industries. London: NESTA and ARC Centre of Excellence for Creative Industries and Innovation. Accessed July 6, 2015.

https://www.nesta.org.uk/sites/default/files/a dynamic mapping of the creati ve industries.pdf

Berelson, Bernard, and Patricia Salter. 1973. "Majority and Minority Americans: an analysis of magazine fiction." In The Manufacture of News: Social Problems, Deviance and the Mass Media, edited by Stanley Cohen and Jock Young. London: Phaidon Press.

Bhabha, Homi. 1994. The location of culture. New York: Routledge. 
Bigelow, Martha. 2011. "(Con)texts for Cultural and Linguistic Hybridity among Somali Diaspora Youth." The New Educator 7, 27-43.

Bose, Martina. 2005. "Difference and exclusion at work in the club culture economy." International Journal of Cultural Studies 8 (4): 427-444.

Caves, Richard. 2000. Creative Industries: Contracts between Art and Commerce. Cambridge: Harvard University Press.

Creative Industries Innovation Centre. 2013. Valuing Australia's Creative Industries: final report. Brisbane: SGS Economics and Planning Pty Ltd.

Conor, Bridget, Rosalind Gill and Stephanie Taylor 2015. “Gender and Creative Labour." The Sociological Review 63, 1-22.

Creative and Cultural Skills. 2008. Creative and cultural industry: Impact and footprints 08-09. London: Creative and Cultural Skills.

Cultural Ministers Council. February 2008. Building a Creative Innovation Economy. Accessed July 6, 2015.

http://mcm.arts.gov.au/sites/default/files/building-a-creative-innovationeconomy.pdf

Davidson, Monica. 2015. "Knocking on a locked door: women in Australian feature films." Lumina 14. Accessed July 10, 2015.

http://www.aftrs.edu.au/media/books/lumina/lumina14-ch1-1/index.html

Davis, Kathy. 2008. "Intersectionality as a buzzword: a sociology of science perspective on what makes a feminist theory successful." Feminist Theory 9(1): 67-85.

de Beauvoir, Simone. 1993. Deuxieme sexe. New York: Alfred A. Knopf.

Deloitte Access Economics. 2015. Australia's Digital Pulse: key challenges for our nation - digital skills, jobs, education. Sydney: Australian Computer Society.

Dodd, Fiona. 2012. "Women leaders in the creative industries: a baseline study." International Journal of Gender and Entrepreneurship 4 (2), 153-178.

Eikhof, Doris, and Chris Warhurst2013. "The promised land? Why social inequalities are systemic in the creative industries." Employee Relations 35 (5), 495-508.

Fibbi, Rosita, Mathias Lerch. and Philippe Wanner. 2006. "Unemployment and discrimination against youth of immigrant origin in Switzerland: when the name makes a difference." Journal of International Migration and Integration 7 (3), 351-366. 
Flew, Terry. 2014. "Creative industries - a new pathway." Intermedia 42 (1), 1113.

Florida, Richard. 2002. The rise of the creative class. New York: Basic Books.

Gill, Rosalind. 2002. "Cool, creative and egalitarian? Exploring gender in projectbased new media work in Europe." Information, Communication \& Society 5(1), 70-89.

Gill, Rosalind, and Andy Pratt. 2008. "In the social factory? Immaterial labour, precariousness and cultural work." Theory, Culture \& Society 25 (7-8), 1-30.

Hage, Ghassan. 2002. "Multiculturalism and White Paranoia in Australia." Journal of International Migration and Integration 3 (3), 417-437.

Hall, Stuart. 1992. Rethinking New Ethnicities: Three Blind Mice (One Black, One White, One Hybrid). London: University of East London.

Haraway, Donna. 1988. "Situated knowledges: the science question in feminism and the privilege of partial perspective." Feminist Studies 14 (3), 575-599.

Harris, Anne. 2013. "The Ellen DeGeneration: nudging bias in the creative arts classroom." Australian Educational Researcher 40(1): 77-90.

Hearn, Greg, Ruth Bridgstock, Ben Goldsmith and Jess Rodgers. 2013. Creative work beyond the creative industries. Cheltenham: Edward Elgar Publishing.

Higgs, Peter, Stuart Cunningham and Hasan Bakhshi. 2008. Beyond the creative industries: mapping the creative economy in the United Kingdom. London: NESTA.

Lauzen, Martha. 2012. The celluloid ceiling: behind-the-scenes film employment of women in the top 250 films of 2012. San Diego: Center for the Study of Women in Film and Television. Accessed July 15, 2015.

http://womenintvfilm.sdsu.edu/research.html

Lee and Low Books. 2013. "Where's the diversity? A look at the Emmy Awards and TV." The Open Book: a blog on race, diversity, education and children's books. Accessed July 16, 2015. http://blog.leeandlow.com/2013/09/18/wheres-thediversity-a-look-at-the-emmy-awards-and-tv/

Lee and Low Books. 2013a. "Where's the diversity? The Tony Awards looks in the mirror." The Open Book: a blog on race, diversity, education and children's books. Accessed July 16, 2015. http://blog.leeandlow.com/2013/06/06/wheresthe-diversity-the-tony-awards-looks-in-the-mirror/

Lee and Low Books. 2013b. "Why hasn't the number of multicultural books increased in eighteen years?" The Open Book: a blog on race, diversity, education and children's books. Accessed July 16, 2015. 
http://blog.leeandlow.com/2013/06/17/why-hasnt-the-number-ofmulticultural-books-increased-in-eighteen-years/

Lee and Low Books. 2013c. "Where's the diversity? The NY Times Top 10 Bestsellers List." The Open Book: a blog on race, diversity, education and children's books. Accessed July 17, 2015. http://blog.leeandlow.com/2013/12/10/wheresthe-diversity-the-ny-times-top-10-bestsellers-list/

Lee and Low Books. 2014. "Where's the diversity, Hollywood? 85 years of the Academy Awards." The Open Book: a blog on race, diversity, education and children's books. Accessed July 16, 2015.

http://blog.leeandlow.com/2014/02/20/wheres-the-diversity-hollywood-85years-of-the-academy-awards/

Lee and Low Books. 2014a. "Where's the diversity, Hollywood? Sci-fi and fantasy blockbusters overwhelmingly white, male." The Open Book: a blog on race, diversity, education and children's books. Accessed July 16, 2015.

http://blog.leeandlow.com/2014/07/29/wheres-the-diversity-hollywood-sci-fiand-fantasy-blockbusters-overwhelmingly-white-male/

Lee and Low Books. 2015. "The diversity gap in Silicon Valley." The Open Book: a blog on race, diversity, education and children's books. Accessed July 16, 2015. http://blog.leeandlow.com/2015/03/12/the-diversity-gap-in-silicon-valley/

Leung, Linda. 2005. Virtual Ethnicity: Race, Resistance and the World Wide Web. Aldershot: Ashgate Publishing.

Luttrell, Wendy. 1988. "Different ways of knowing: a feminist perspective on the intersection of gender, race and class in the social construction of knowledge." In SCUTREA 25th Anniversary Conference Proceedings (1970-1997). London:

Standing Conference on University Teaching and Research in the Education of Adults.

Maconie, Stuart. February 4, 2015. "Stuart Maconie: The privileged are taking over the arts - without the grit, pop culture is doomed." In The New Statesman. Accessed July 16, 2015.

http://www.newstatesman.com/culture/2015/01/privileged-are-taking-overarts-without-grit-pop-culture-doomed

Marx, Karl. 1974. Das Kapital: a critique of political economy. London: Lawrence and Wishart.

McCall, Leslie. 2005. "The Complexity of Intersectionality." Signs: Journal of Women in Culture and Society 30(3): 1771-1800.

Menger, Pierre-Michel. 2006. "Artistic labour markets: contingent work, excess supply and occupational risk management." In Handbook of the Economics of Art and Culture, Volume 1, edited by Victor Ginsburg and David Throsby, 756-811. Oxford: Elsevier. 
Mulvey, Laura. 2015. “The pleasure principle.” Sight \& Sound 25 (6), 50-51.

Oakley, Kate. 2006. "Include us out - economic development and social policy in the creative industries.” Cultural Trends 15 (4), 255-273.

Oakley, Kate. 2013. "Absentee workers: representation and participation in cultural industries." In Theorizing Cultural Work: Labour, Continuity and Change in the Creative Industries, edited by Mark Banks, Rosalind Gill and Stephanie Taylor, 56-67. London: Routledge.

Phillips, Kim. 2014. Before Orientalism: Asian Peoples and Cultures in European Travel Writing, 1245-1510. Philadelphia: University of Pennsylvania Press.

Richards, Stuart. 2016. "Proud in the middleground: how the creative industries allow the Melbourne queer film festival to bring queer content to audiences." Studies in Australasian Cinema 10(1): 129-142.

Roan, Amanda, and Naomi Stead. 2013. "A 'new institutional' perspective on women's position in architecture: considering the cases of Australia and Sweden." Architectural Theory Review 17 (2-3), 378-398.

Ross, Karen. 1996. Black and White Media: Black images in popular film and television. Cambridge: Polity Press.

Said, Edward. 1995. Orientalism. London: Penguin.

Sang, Katherine, Andrew Dainty and Stephen Ison. 2007. "Gender: a risk factor for occupational stress in the architectural profession." Construction Management and Economics 25, 1305-1317.

Schippers, Mimi. 2007. "Recovering the feminine other: masculinity, femininity, and gender hegemony." Theory \& Society 36 (1), 85-102.

Screenhub. June 4, 2015. "No fun for you darling - the ugly truth in Australian film production." ArtsHub. Accessed July 10, 2015.

http://screen.artshub.com.au/news-article/features/film/screenhub/no-funfor-you-darling-the-ugly-truth-in-australian-film-production-248282

Silberman, Roxane, Richard Alba and Irene Fournier. 2007. "Segmented assimilation in France? Discrimination in the labour market against the second generation." Ethnic and Racial Studies 30 (1), 1-27.

Smallbone, David, Marcello Bertotti and Ignatius Ekanem. 2005. "Diversification in ethnic minority business: the case of Asians in London's creative industries." Journal of Small Business and Enterprise Development 12 (1), 41-56.

Solomos, John, and Les Back. 1996. Racism and Society. London: Macmillan Press. 
Sorrell, Martin. 2015. "Creativity makes a vast contribution to business: we ignore it at our peril." City A.M. Accessed July 7, 2015.

http://www.cityam.com/210306/creativity-makes-vast-contribution-businesswe-ignore-it-our-peril

Soskice, Janet. 1994. “Trinity and 'the Feminine Other'." New Blackfriars 75 (878), 2-17.

Soysal, Levent. 2001. "Diversity of experience, experience of diversity: Turkish migrant youth in Berlin." Cultural Dynamics 13 (1), 5-28.

The Sutton Trust. June 2006. The Educational Backgrounds of Leading Journalists. Accessed July 10, 2015.

http://www.suttontrust.com/researcharchive/educational-backgroundsleading-journalists/

Thanki, Ashika. and Steve Jeffreys. 2007. "Who are the fairest? Ethnic segmentation in London's media production." Work Organisation, Labour and Globalisation 1 (1), 108-118.

Thomson, Paula, E.B. Keehn and Thomas Gumpel. 2009. "Generators and interpretors in a performing arts population." Creativity Research Journal 21, 7291.

Townley, Barbara, Nic Beech and Alan McKinlay. 2009. "Managing in the creative industries: managing the motley crew." Human Relations 62 (7), 939-962.

Wakil, S. Parvez, CM Siddique and FA Wakil. 1981. "Between two cultures: a study in socialization of children of immigrants." Journal of Marriage and Family 43 (4), 929-940. 